\title{
Clinical Significance of the Cardio-Ankle Vascular Index in Postmenopausal Women With Hypercholesterolemia
}

\author{
Takashi Hitsumoto
}

\begin{abstract}
Background: The cardio-ankle vascular index (CAVI) is a physiological indicator of arterial elasticity. However, limited information regarding the clinical significance of the CAVI in patients with hypercholesterolemia is available. This cross-sectional study aimed to elucidate the clinical significance of the CAVI for the primary prevention of cardiovascular disease (CVD) among postmenopausal women with hypercholesterolemia.
\end{abstract}

Methods: A total of 168 untreated postmenopausal hypercholesterolemic women (low-density lipoprotein cholesterol levels $\geq 140 \mathrm{mg}$ / $\mathrm{dL}$, mean age \pm standard deviation, $63 \pm 10$ years) with no history of CVD events were enrolled. The CAVI was measured using commercial devices, after which, its relationships with various clinical parameters, such as carotid artery ultrasonography findings and CVD biomarkers, were examined.

Results: A significant positive correlation was observed between the CAVI and maximum intima-media thickness of the common carotid artery (max-C-IMT), which was evaluated using carotid artery ultrasonography $(\mathrm{r}=0.49, \mathrm{P}<0.001)$. Regarding CVD biomarkers, the CAVI was significantly correlated with estimated glomerular filtration rate $(\mathrm{r}=-0.18, \mathrm{P}<0.001)$, high-sensitivity $\mathrm{C}$-reactive protein $(\mathrm{r}$ $=0.36, \mathrm{P}<0.001)$, whole blood passage time as a marker of blood rheology $(r=0.41, P<0.001)$, and skin autofluorescence as a marker of advanced glycation end products in tissues $(\mathrm{r}=0.46, \mathrm{P}<0.001)$, although no significant correlation was noted between serum lipid parameters and the CAVI. Multiple regression analysis identified max-C-IMT $(\beta=0.35, \mathrm{P}<0.001)$, whole blood passage time $(\beta=$ $0.18, \mathrm{P}=0.007)$, skin autofluorescence $(\beta=0.17, \mathrm{P}=0.011)$, and age $(\beta=0.16, P=0.018)$ as variables independently associated with CAVI.

Conclusion: The present study indicated that the CAVI is an essential CVD risk factor among postmenopausal women with hypercholesterolemia. Moreover, impaired blood rheology and increase of skin autofluorescence were associated with elevated CAVI in such patients.

Manuscript submitted April 21, 2021, accepted May 4, 2021

Published online May 25, 2021

Hitsumoto Medical Clinic, 2-7-7, Takezakicyou, Shimonoseki City, Yamaguchi 750-0025, Japan. Email: thitsu@jcom.home.ne.jp

doi: https://doi.org/10.14740/jocmr4509
Keywords: Cardio-ankle vascular index; Hypercholesterolemia; Postmenopausal women; Carotid atherosclerosis; Skin autofluorescence; Blood rheology; Cardiovascular risk factors

\section{Introduction}

Hypercholesterolemia, especially increased low-density lipoprotein cholesterol (LDL-C), has been known as one of the most important risk factors for cardiovascular disease (CVD) [1-3]. Moreover, previous studies have reported that blood cholesterol levels increase progressively in postmenopausalstage women [4]. However, several clinical studies on primary CVD events have indicated that cholesterol-lowering therapy is not always effective in women $[5,6]$. In fact, several healthy elderly women have exhibited hypercholesterolemia alone without a history of CVD events in daily clinical practice. Thus, novel therapeutic strategies, apart from lowering LDL$\mathrm{C}$ levels, should be considered to prevent primary CVD events in postmenopausal women with hypercholesterolemia.

The cardio-ankle vascular index (CAVI) is a physiological indicator of arterial elasticity [7]. Recent clinical studies have emphasized the clinical importance of the CAVI as a CVD risk factor [8-11]. Moreover, several researchers have reported associations between serum lipid parameters, including LDL-C levels, and the CAVI [12-14]. However, limited information regarding the clinical significance of the CAVI in patients with hypercholesterolemia has been available. Therefore, the present study sought to elucidate the clinical significance of the CAVI for primary CVD prevention in postmenopausal women with hypercholesterolemia.

\section{Materials and Methods}

\section{Patients}

Between January 2017 and December 2019, this study enrolled 168 untreated, postmenopausal, hypercholesterolemic women (LDL-C levels $\geq 140 \mathrm{mg} / \mathrm{dL}$; mean age: $63 \pm 10$ years) without history of CVD, such as coronay artery disease, stroke, peripheral artery disease, and heart failure, who visited the Hitsumoto Medical Clinic. Previous studies have reported that various antihypertensive and antidiabetic drugs can affect 
CAVI [15-18]. Thus, subjects receiving such medications were also excluded. This study was approved by the Ethics Committee of the Hitsumoto Medical Clinic (approval number: HMCR-2017-1) and was conducted in accordance with the ethical standards of the responsible agency for humans and the Declaration of Helsinki.

\section{Measurement of the CAVI}

CAVI was measured using commercially available medical equipment (VaSera CAVI device, Fukuda Denshi Co., Ltd, Tokyo, Japan), which have been reported in previous papers $[7,19]$. In brief, CAVI is calculated using blood pressure and pulse wave velocity, basing its concept on the stiffness parameter $\beta$ and Bramwell-Hill equations which is taken after lying on one's back for about $10 \mathrm{~min}$ in a quiet room [7]. In this study, the higher CAVI value on the left or right side was selected as the measurement, and patients with arteriosclerosis obliterans (ankle-brachial blood pressure ratio $<0.9$ ) and/or chronic atrial fibrillation were excluded due to unstable measurements. A previous study indicated that the average coefficient of variation for CAVI was $3.8 \%$, which is sufficiently small for clinical use, indicating good reproducibility [7].

\section{Carotid artery ultrasonographic examination}

Carotid ultrasonography was performed using a commercial device, the 3.0 MHz convex array probe (HI VISION Avius, Hitachi Medical Corporation, Tokyo, Japan). The maximum intima-media thickness (max-C-IMT) of the common caroditd artery (CCA), defined as the largest IMT measured at the CCA, was used as the surrogate marker for CVD events in this study since reports have indicated its use as a predictor of CVD events [20]. All measurements were performed by same experienced physician who was blinded to the other data of the subjects.

\section{Evaluation of CVD risk factors}

The degree of obesity was evaluated using body mass index, and a smoker was defined somone who smoked within the past month. Blood samples were collected after fasting for 12 $\mathrm{h}$ or more, wherein serum lipid, blood glucose, hemoglobin A1c $(\mathrm{HbA1c})$, creatinine, high-sensitivity C-reactive protein (hs-CRP) levels, and whole blood passage time (WBPT) were measured using standard laboratory procedures. For lipid profiling, serum LDL-C concentrations were evaluated using the Friedewald formula [21], excluding subjects with serum triglyceride concentrations of $\geq 400 \mathrm{mg} / \mathrm{dL}$ given the formula's lack of reliability for these levels. Meanwhile, non-HDL-C levels were determined using this indicated formula (total cholesterol levels - HDL-C levels), and the triglyceride-glucose index $(\ln$ (fasting triglycerides $(\mathrm{mg} / \mathrm{dL}) \times$ fasting plasma glucose $(\mathrm{mg} / \mathrm{dL}) / 2)$ ) was calculated as an insulin resistance marker [22]. Moreover, the estimated glomerular filtration rate (eGFR) was calculated using the Japanese diagnostic method
[23]. In particular, blood rheology was measured using commercially available medical devices (MC-FAN HR300 rheometer, MCLaboratory Inc., Tokyo, Japan; width: $7.5 \mu \mathrm{m}$, depth $4.5 \mu \mathrm{m}$, length $30 \mu \mathrm{m}$ ), wherein themicrochannel transit time of $100 \mu \mathrm{L}$ saline was first measured as a control before measuring the same parameters of the same volume of the patient's whole blood treated with 5\% heparin $[24,25]$. The subjects' WBPT was then determined after saline transit time correction, which previous reports have described as having good reproducibility [24]. Skin autofluorescence (AF), which reflects the amount of advanced glycation end products (AGEs) in vivo and is expressed as the average light internsity per nanometer of $300-420 \mathrm{~nm}$, was also measured using commercially available medical devices given its reliability (AGEReader ${ }^{\mathrm{TM}}$; DiagnOptics, Groningen, The Netherlands) [19, 26]. With the patient seated, measurements were taken on the volar side of the lower arm, about 10 - $15 \mathrm{~cm}$ below the elbow. Of note, pentosidine, one of the major AGEs components obtained from major skin biopsies, has been reported to significantly correlate with skin AF [27].

\section{Statistical analysis}

Statistical processing was performed using MedCalc for Windows (version 14.8.1; MedCalc Software, Ostend, Belgium) and StatView J5.0 (HULINKS, Tokyo, Japan). Correlation coefficients were evaluated using the Pearson or Spearman rankorder correlation analysis, and multiple regression analysis was performed with CAVI or max-C-IMT as the dependent variable. For the explanatory variables, eight significant factors in the univariate analysis were selected (age, smoker, HbA1c, eGFR, hs-CRP, WBPT, skin AF, max-C-IMT) for CAVI, while seven explanatory variables (age, smoker, eGFR, hs-CRP, WBPT, skin AF, CAVI) for max-IMT were inserted and analyzed. A Pvalue of $<0.05$ was judged to be statistically significant.

\section{Results}

\section{Clinical characteristics}

Table 1 summarizes the patients' clinical characteristics. Accordingly, they had a mean LDL-C of $165 \pm 21 \mathrm{mg} / \mathrm{dL}$, ranging from 140 to $271 \mathrm{mg} / \mathrm{dL}$ (median value: $159 \mathrm{mg} / \mathrm{dL}$ ), but the CAVI had a mean value of $8.4 \pm 1.2$, ranging from 6.7 to 11.8 $\mathrm{mg} / \mathrm{dL}$ (median value: 8.2 ).

\section{Correlations between the CAVI and various clinical pa- rameters}

Table 2 summarizes the correlations between CAVI and various clinical parameters. CAVI had a significant positive correlation with max-C-IMT and with CVD risk factors including age, smoking habits, HbAlc, hs-CRP, WBPT, and skin AF. However, a significant negative correlation was observed between CAVI and eGFR. Accordingly, no significant correla- 
Table 1. Baseline Clinical Characteristics of the Patients

\begin{tabular}{ll}
\hline $\mathbf{n}$ & $\mathbf{1 6 8}$ \\
\hline Age (years) & $63 \pm 10$ \\
Body mass index $\left(\mathrm{kg} / \mathrm{m}^{2}\right)$ & $21.8 \pm 4.0$ \\
Smoker, n (\%) & $12(7)$ \\
\hline Systolic blood pressure (mm Hg) & $122 \pm 12$ \\
\hline Diastolic blood pressure (mm Hg) & $75 \pm 9$ \\
Pulse rate (/min) & $68 \pm 10$ \\
Total cholesterol (mg/dL) & $258 \pm 25$ \\
LDL-cholesterol (mg/dL) & $165 \pm 21$ \\
Triglyceride (mg/dL) & $99 \pm 52$ \\
HDL-cholesterol (mg/dL) & $73 \pm 13$ \\
Non-HDL-cholesterol (mg/dL) & $185 \pm 24$ \\
LDL-cholesterol/HDL-cholesterol & $2.3 \pm 0.6$ \\
Triglyceride/HDL-cholesterol & $1.5 \pm 0.9$ \\
Fasting blood glucose (mg/dlL) & $91 \pm 22$ \\
\hline Hemoglobin Alc (\%) & $5.6 \pm 0.9$ \\
Triglyceride-glucose index & $8.2 \pm 0.6$ \\
\hline eGFR (mL/min/1.73 m²) & $67 \pm 21$ \\
hs-CRP (mg/dL) & $0.050(0.020,0.110)$ \\
\hline Log-hs-CRP (mg/dL) & $-1.4 \pm 0.7$ \\
\hline WBPT (s) & $56 \pm 13$ \\
Skin autofluorescence (AU) & $2.4 \pm 0.7$ \\
\hline Max-C-IMT (mm) & $0.9 \pm 0.4$ \\
CAVI & $8.4 \pm 1.2$ \\
\hline
\end{tabular}

Continuous values are mean $\pm \mathrm{SD}$. hs-CRP levels are presented as the median (25\%, 75\%). LDL: low-density lipoprotein; HDL: high-density lipoprotein; eGFR: estimated glomerular filtration rate; hs-CRP: highsensitivity C-reactive protein; WBPT: whole blood passage time; AU: arbitrary unit; Max-C-IMT: maximum intima-media thickness in the common carotid artery; CAVI: cardio-ankle vascular index.

tions were noted between CAVI and serum lipid parameters including LDL-C levels.

\section{Multiple regression analysis}

Table 3 shows the results of multiple regression analyses for CAVI and max-C-IMT. For the dependent variable CAVI, four explanatory variables (max-C-IMT, WBPT, skin AF, age) were selected as independent contributors (Table 3, section A). Meanwhile, for max-C-IMT as the dependent variable, three explanatory variables (CAVI, skin AF, age) were selected (Table 3, section B).

\section{Discussion}

The present study elucidated the clinical significance of the CAVI as a risk factor for CVD among postmenopausal women
Table 2. Correlations Between CAVI and Various Clinical Parameters

\begin{tabular}{lll}
\hline & r & P value \\
\hline Age & 0.33 & $<0.001$ \\
\hline Body mass index & 0.01 & 0.902 \\
Smoker (no = 0, yes =1) & 0.29 & $<0.001$ \\
\hline Systolic blood pressure & 0.14 & 0.067 \\
Diastolic blood pressure & -0.10 & 0.194 \\
Pulse rate & 0.08 & 0.256 \\
Total cholesterol & 0.00 & 0.949 \\
LDL cholesterol & 0.06 & 0.408 \\
Triglyceride & 0.00 & 0.980 \\
\hline HDL cholesterol & -0.09 & 0.236 \\
Non-HDL cholesterol & 0.06 & 0.449 \\
\hline LDL cholesterol/HDL cholesterol & 0.08 & 0.257 \\
Triglyceride/HDL cholesterol & 0.00 & 0.954 \\
\hline Fasting blood glucose & 0.11 & 0.142 \\
Hemoglobin A1c & 0.33 & $<0.001$ \\
\hline Triglyceride-glucose index & 0.07 & 0.344 \\
eGFR & -0.18 & 0.017 \\
\hline Log-hs-CRP & 0.36 & $<0.001$ \\
WBPT & 0.41 & $<0.001$ \\
\hline Skin autofluorescence & 0.46 & $<0.001$ \\
\hline Max-C-IMT & 0.49 & $<0.001$ \\
\hline
\end{tabular}

r expressed correlation coefficient. LDL: low-density lipoprotein; HDL: high-density lipoprotein; eGFR: estimated glomerular filtration rate; hsCRP: high-sensitivity C-reactive protein; WBPT: whole blood passage time; Max-C-IMT: maximum intima-media thickness in the common carotid artery; CAVI: cardio-ankle vascular index.

with hypercholesterolemia. Notably, the results of this study showed a close relationship between the CAVI and carotid atherosclerosis, with novel CVD risk factors, such as WBPT and skin AF, being independently associated with the CAVI. Nevertheless, no relationship had been observed between CAVI and serum lipid parameters including LDL-C.

Several clinical studies have reported that carotid atherosclerosis, which is evaluated through carotid artery ultrasonography, can indicate systemic atherosclerosis and be used as a predictor of CVD events [20, 28, 29]. However, several researchers have indicated significant associations between the CAVI and parameters of carotid artery ultrasonography [3032]. The findings of the present study also indicated that the max-C-IMT, one of the parameters for carotid atherosclerosis, was significantly associated with the CAVI. Kokubo et al, who examined the relationships between three carotid atherosclerosis parameters (mean IMT, max-IMT, and max-C-IMT) and primary CVD events in a Japanese cohort, reported that the max-C-IMT was the most useful parameter for predicting CVD events, such as both ischemic heart disease and stroke [20]. Thus, the independent association between the CAVI and 
Table 3. Multiple Regression Analyses for CAVI and Max-C-IMT

\begin{tabular}{llll}
\hline Explanatory factor & $\boldsymbol{\beta}$ & P value \\
\hline A & & & \\
\multicolumn{1}{l}{ Max-C-IMT } & 0.35 & $<0.001$ \\
& WBPT & 0.18 & 0.007 \\
& Skin autofluorescence & 0.17 & 0.011 \\
Age & 0.16 & 0.018 \\
Hemoglobin A1c & 0.13 & 0.064 \\
Log-hs-CRP & 0.11 & 0.073 \\
Smoker & 0.06 & 0.319 \\
eGFR & -0.05 & 0.503 \\
B & & \\
CAVI & 0.45 & $<0.001$ \\
Skin autofluorescence & 0.17 & 0.023 \\
Age & 0.16 & 0.040 \\
WBPT & 0.14 & 0.092 \\
eGFR & -0.13 & 0.124 \\
Smoker & 0.11 & 0.176 \\
Log-hs-CRP & 0.07 & 0.412 \\
\hline
\end{tabular}

For section $A$ : subordinate factor is CAVI. $R^{2}=0.48, P<0.001$. For section $B$ : subordinate factor is Max-C-IMT. $R^{2}=0.30, P<0.001$. Explanatory factors were selected by significant variables in univariate analysis. Max-C-IMT: maximum intima-media thickness in the common carotid artery; WBPT: whole blood passage time; hs-CRP: high-sensitivity C-reactive protein; eGFR: estimated glomerular filtration rate; $\beta$ : standardized regression coefficient; CAVI: cardio-ankle vascular index; $R^{2}$ : coefficient of determination.

max-C-IMT observed herein suggests that the CAVI is an essential predictor for primary CVD events, such as ischemic heart disease and stroke, among postmenopausal women with hypercholesterolemia.

The association between the CAVI and LDL-C remains controversial. Several researchers have reported that the CAVI was significantly associated with LDL-C [12, 33, 34]. However, Homma et al reported that the CAVI was inversely associated with LDL-C among patients with early-stage atherosclerosis [35]. Conversely, other reports, including the present study, indicated no association between CAVI and LDL-C [36, 37]. Several studies have emphasized the importance of serum lipid parameters, apart from LDL-C, in the occurrence of CVD events [38-40]. However, the results presented herein indicated no significant association between various serum lipid parameters and the CAVI. Thus, the present study suggests the need for considering other factors contributing to arterial stiffness, aside from serum lipid parameters, among postmenopausal women with hypercholesterolemia.

Hemorheological impairments have been considered an essential factor in the incidence of CVD events, as well as the progression of atherosclerosis [41-43]. Moreover, recent clinical studies have elucidated that the WBPT estimated using the MC-FAN can be a considerable CVD risk factor [25, 43, 44]. However, several researchers have highlighted the importance of vasa vasorum flow in arterial function [45, 46]. Given that the microchannel formation of MC-FAN was $7 \mu \mathrm{m}$ wide and $4.5 \mu \mathrm{m}$ deep, the WBPT may perhaps have the ability to reflect capillary flow, including that within the vasa vasorum. To what extent collected peripheral venous blood represents vasa vasorum flow in the arterial wall remains unknown. One reason for the significant association between the WBPT and CAVI may be the increased arterial stiffness due to hemorheological impairment in the vasa vasorum. Several clinical studies have emphasized that smoking is one of the essential factors for increased WBPT [47, 48]. Moreover, smoking habits and their cessation have been reported to be associated with the CAVI $[19,49]$. Although the number of smokers included herein was relatively low $(7 \%)$, smoking habits were not identified as independent variables for the CAVI. Nevertheless, postmenopausal women with hypercholesterolemia who engage in smoking habits should be advised to cease the same from the perspective of blood rheology and arterial elasticity.

Basic studies have reported that AGEs or their receptors are associated with calcification and proliferation in vascular cells [50-52]. Moreover, the independent association between skin AF and the CAVI observed herein may have been attributed to the crucial role AGEs play in the progression of arterial stiffness among postmenopausal women with hypercholesterolemia. Several studies have reported that lifestyle habits, such as physical activity, smoking habits, and diet contents, were closely associated with skin AF [19, 53, 54]. Hence, healthy lifestyle habits are essential for maintaining low skin AF and arterial function. However, several reports have elucidated that statin, one of the antilipidemic agents, inhibits AGEs-induced vascular dysfunction $[55,56]$. Thus, statins may be used for hypercholesterolemic patients with high skin AF, which can consequently decrease the risk for primary CVD events.

\section{Limitations}

Several limitations of this study should be acknowledged. First, a significant number of patients did not undergo definitive examinations for the diagnosis of CVDs, such as angiography, computed tomography, magnetic resonance imaging, and echocardiography, possibly missing asymptomatic CVD patients. Second, this was a single-center, cross-sectional study with a relatively small sample size. Large-scale studies, including interventional therapies, are desired to elucidate the clinical importance of CAVI as a risk factor for CVD in postmenopausal, hypercholesetrolemic women.

\section{Conclusions}

The present study indicated that the CAVI is an essential risk factor for CVD among postmenopausal women with hypercholesterolemia. Moreover, impaired blood rheology and increase of skin AF were closely associated with elevated CAVI among the same patients. Nevertheless, further large-scale prospective investigations that include intervention therapies are required to validate the results of the present study. 


\section{Acknowledgments}

None to declare.

\section{Financial Disclosure}

None to declare.

\section{Conflict of Interest}

None to declare.

\section{Informed Consent}

Informed consent was obtained from all participants in this study.

\section{Author Contributions}

The author was involved in preparing the study design as well as in the acquisition, analysis, and interpretation of data.

\section{Data Availability}

The author declares that data supporting the findings of this study are available within the article.

\section{References}

1. Stamler J, Wentworth D, Neaton JD. Is relationship between serum cholesterol and risk of premature death from coronary heart disease continuous and graded? Findings in 356,222 primary screenees of the Multiple Risk Factor Intervention Trial (MRFIT). JAMA. 1986;256(20):28232828.

2. Wakugami K, Iseki K, Kimura Y, Okumura K, Ikemiya Y, Muratani H, Fukiyama K. Relationship between serum cholesterol and the risk of acute myocardial infarction in a screened cohort in Okinawa, Japan. Jpn Circ J. 1998;62(1):7-14.

3. Imano H, Noda H, Kitamura A, Sato S, Kiyama M, Sankai T, Ohira T, et al. Low-density lipoprotein cholesterol and risk of coronary heart disease among Japanese men and women: the Circulatory Risk in Communities Study (CIRCS). Prev Med. 2011;52(5):381-386.

4. Kreisberg RA, Kasim S. Cholesterol metabolism and aging. Am J Med. 1987;82(1B):54-60.

5. Walsh JM, Grady D. Treatment of hyperlipidemia in women. JAMA. 1995;274(14):1152-1158.

6. Walsh JM, Pignone M. Drug treatment of hyperlipidemia in women. JAMA. 2004;291(18):2243-2252.
7. Shirai K, Utino J, Otsuka K, Takata M. A novel blood pressure-independent arterial wall stiffness parameter; cardio-ankle vascular index (CAVI). J Atheroscler Thromb. 2006;13(2):101-107.

8. Gohbara M, Iwahashi N, Sano Y, Akiyama E, Maejima N, Tsukahara K, Hibi K, et al. Clinical impact of the cardioankle vascular index for predicting cardiovascular events after acute coronary syndrome. Circ J. 2016;80(6):14201426.

9. Hitsumoto T. Clinical Usefulness of the Cardio-Ankle Vascular Index as a predictor of primary cardiovascular events in patients with chronic kidney disease. J Clin Med Res. 2018;10(12):883-890.

10. Saiki A, Ohira M, Yamaguchi T, Nagayama D, Shimizu N, Shirai K, Tatsuno I. New horizons of arterial stiffness developed using cardio-ankle vascular index (CAVI). J Atheroscler Thromb. 2020;27(8):732-748.

11. Hitsumoto T. Correlation between the cardio-ankle vascular index and renal resistive index in patients with essential hypertension. Cardiol Res. 2020;11(2):106-112.

12. Nagayama D, Watanabe Y, Saiki A, Shirai K, Tatsuno I. Lipid parameters are independently associated with cardio-ankle vascular index (CAVI) in healthy Japanese subjects. J Atheroscler Thromb. 2018;25(7):621-633.

13. Yamaguchi T, Shirai K, Nagayama D, Nakamura S, Oka R, Tanaka S, Watanabe Y, et al. Bezafibrate ameliorates arterial stiffness assessed by cardio-ankle vascular index in hypertriglyceridemic patients with type 2 diabetes mellitus. J Atheroscler Thromb. 2019;26(7):659-669.

14. Shimizu Y, Nakazato M, Sekita T, Kadota K, Yamasaki H, Takamura N, Aoyagi K, et al. Association of arterial stiffness and diabetes with triglycerides-to-HDL cholesterol ratio for Japanese men: the Nagasaki Islands Study. Atherosclerosis. 2013;228(2):491-495.

15. Kurata M, Okura T, Watanabe S, Irita J, Enomoto D, Johtoku M, Miyoshi K, et al. Effects of amlodipine and candesartan on arterial stiffness estimated by cardio-ankle vascular index in patients with essential hypertension: A 24-week study. Curr Ther Res Clin Exp. 2008;69(5):412422.

16. Shirai K, Utino J, Saiki A, Endo K, Ohira M, Nagayama D, Tatsuno I, et al. Evaluation of blood pressure control using a new arterial stiffness parameter, cardio-ankle vascular index (CAVI). Curr Hypertens Rev. 2013;9(1):6675.

17. Nagayama D, Saiki A, Endo K, Yamaguchi T, Ban N, Kawana H, Ohira M, et al. Improvement of cardio-ankle vascular index by glimepiride in type 2 diabetic patients. Int J Clin Pract. 2010;64(13):1796-1801.

18. Tahara N, Yamagishi SI, Bekki M, Kodama N, Nakamura T, Sugiyama Y, Oshige T, et al. Anagliptin, a dipeptidyl peptidase-4 inhibitor ameliorates arterial stiffness in association with reduction of remnant-like particle cholesterol and alanine transaminase levels in type 2 diabetic patients. Curr Vasc Pharmacol. 2016;14(6):552-562.

19. Hitsumoto T. Relationships between skin autofluorescence and cardio-ankle vascular index in japanese male patients with metabolic syndrome. Cardiol Res. 2019;10(3):172180. 
20. Kokubo Y, Watanabe M, Higashiyama A, Nakao YM, Nakamura F, Miyamoto Y. Impact of intima-media thickness progression in the common carotid arteries on the risk of incident cardiovascular disease in the suita study. J Am Heart Assoc. 2018;7(11):e007720.

21. Friedewald WT, Levy RI, Fredrickson DS. Estimation of the concentration of low-density lipoprotein cholesterol in plasma, without use of the preparative ultracentrifuge. Clin Chem. 1972;18(6):499-502.

22. Simental-Mendia LE, Rodriguez-Moran M, GuerreroRomero F. The product of fasting glucose and triglycerides as surrogate for identifying insulin resistance in apparently healthy subjects. Metab Syndr Relat Disord. 2008;6(4):299304.

23. Imai E, Horio M, Nitta K, Yamagata K, Iseki K, Hara S, Ura N, et al. Estimation of glomerular filtration rate by the MDRD study equation modified for Japanese patients with chronic kidney disease. Clin Exp Nephrol. 2007;11(1):4150 .

24. Kikuchi Y, Sato K, Mizuguchi Y. Modified cell-flow microchannels in a single-crystal silicon substrate and flow behavior of blood cells. Microvasc Res. 1994;47(1):126139.

25. Hitsumoto T. Clinical impact of hemorheology on subclinical myocardial injury in patients with hypertension. J Clin Med Res. 2018;10(12):928-935.

26. Nomoto K, Yagi M, Arita S, Hamada U, Yonei Y. A survey of fluorescence derived from advanced glycation end products in the skin of Japanese: differences with age and measurement location. Anti Aging Med. 2012;9(5):119124.

27. Meerwaldt R, Graaff R, Oomen PHN, Links TP, Jager JJ, Alderson NL, Thorpe SR, et al. Simple non-invasive assessment of advanced glycation endproduct accumulation. Diabetologia. 2004;47(7):1324-1330.

28. O'Leary DH, Polak JF, Kronmal RA, Manolio TA, Burke GL, Wolfson SK, Jr. Carotid-artery intima and media thickness as a risk factor for myocardial infarction and stroke in older adults. Cardiovascular Health Study Collaborative Research Group. N Engl J Med. 1999;340(1):14-22.

29. Polak JF, O'Leary DH. Carotid Intima-Media Thickness as Surrogate for and Predictor of CVD. Glob Heart. 2016;11(3):295-312 e293.

30. Gomez-Marcos MA, Recio-Rodriguez JI, Patino-Alonso MC, Agudo-Conde C, Gomez-Sanchez L, Gomez-Sanchez M, Rodriguez-Sanchez E, et al. Cardio-ankle vascular index is associated with cardiovascular target organ damage and vascular structure and function in patients with diabetes or metabolic syndrome, LOD-DIABETES study: a case series report. Cardiovasc Diabetol. 2015;14:7.

31. Kadota K, Takamura N, Aoyagi K, Yamasaki H, Usa T, Nakazato M, Maeda T, et al. Availability of cardio-ankle vascular index (CAVI) as a screening tool for atherosclerosis. Circ J. 2008;72(2):304-308.

32. Hitsumoto T. Relationships between the cardio-ankle vascular index and pulsatility index of the common carotid artery in patients with cardiovascular risk factors. J Clin Med Res. 2019;11(8):593-599.

33. Zhao X, Bo L, Zhao H, Li L, Zhou Y, Wang H. Cardio- ankle vascular index value in dyslipidemia patients affected by cardiovascular risk factors. Clin Exp Hypertens. 2018;40(4):312-317.

34. Miyashita Y, Endo K, Saiki A, Ban N, Nagumo A, Yamaguchi T, Kawana H, et al. Effect of ezetimibe monotherapy on lipid metabolism and arterial stiffness assessed by cardio-ankle vascular index in type 2 diabetic patients. J Atheroscler Thromb. 2010;17(10):1070-1076.

35. Homma S, Kato K, Hayashi J, Yamamoto M. Negative associations between arterial stiffness parameter evaluated by cardio-ankle vascular index and serum low-density lipoprotein cholesterol concentration in early-stage atherosclerosis. Angiology. 2015;66(2):143-149.

36. Lee JA, Kim DH, Yu SJ, Oh DJ, Yu SH. Association of serum albumin and homocysteine levels and cardio-ankle vascular index in patients with continuous ambulatory peritoneal dialysis. Korean J Intern Med. 2006;21(1):3338.

37. Zheng X, Wei Q, Long J, Gong L, Chen H, Luo R, Ren $\mathrm{W}$, et al. Gender-specific association of serum uric acid levels and cardio-ankle vascular index in Chinese adults. Lipids Health Dis. 2018;17(1):80.

38. Toth PP. Triglyceride-rich lipoproteins as a causal factor for cardiovascular disease. Vasc Health Risk Manag. 2016;12:171-183

39. Mizuno K, Nakaya N, Teramoto T, Yokoyama S, Ohashi Y, Ueki A, Takahashi S, et al. Usefulness of LDL-C-related parameters to predict cardiovascular risk and effect of pravastatin in mild-to-moderate hypercholesterolemia. J Atheroscler Thromb. 2012;19(2):176-185.

40. Yang SH, Du Y, Li XL, Zhang Y, Li S, Xu RX, Zhu CG, et al. Triglyceride to high-density lipoprotein cholesterol ratio and cardiovascular events in diabetics with coronary artery disease. Am J Med Sci. 2017;354(2):117-124.

41. Cowan AQ, Cho DJ, Rosenson RS. Importance of blood rheology in the pathophysiology of atherothrombosis. Cardiovasc Drugs Ther. 2012;26(4):339-348.

42. Tzoulaki I, Murray GD, Lee AJ, Rumley A, Lowe GD, Fowkes FG. Relative value of inflammatory, hemostatic, and rheological factors for incident myocardial infarction and stroke: the Edinburgh Artery Study. Circulation. 2007;115(16):2119-2127.

43. Kotani K, Satoh N, Yamada K, Taniguchi N, Shimatsu A. The influence of metabolic syndrome and chronic kidney disease on hemorheology assessed by the microchannel method. J Physiol Anthropol. 2010;29(5):157-160.

44. Hitsumoto T. Usefulness of the whole blood passage time as a predictor of primary cardiovascular events in patients with traditional cardiovascular risk factors. Cardiol Res. 2018;9(4):231-238.

45. Angouras D, Sokolis DP, Dosios T, Kostomitsopoulos N, Boudoulas H, Skalkeas G, Karayannacos PE. Effect of impaired vasa vasorum flow on the structure and mechanics of the thoracic aorta: implications for the pathogenesis of aortic dissection. Eur J Cardiothorac Surg. 2000;17(4):468-473.

46. Shimizu K, Takahashi M, Sato S, Saiki A, Nagayama D, Harada M, Miyazaki C, et al. Rapid rise of cardio-ankle vascular index may be a trigger of cerebro-cardiovascular 
events: proposal of smooth muscle cell contraction theory for plaque rupture. Vasc Health Risk Manag. 2021;17:3747.

47. Shimada S, Hasegawa K, Wada H, Terashima S, Satoh-Asahara N, Yamakage H, Kitaoka S, et al. High blood viscosity is closely associated with cigarette smoking and markedly reduced by smoking cessation. Circ J. 2011;75(1):185-189.

48. Hitsumoto T. Factors affecting impairment of blood rheology in obese subjects. J Cardiol. 2012;60(5):401-406.

49. Noike H, Nakamura K, Sugiyama Y, Iizuka T, Shimizu $\mathrm{K}$, Takahashi M, Hirano K, et al. Changes in cardio-ankle vascular index in smoking cessation. J Atheroscler Thromb. 2010;17(5):517-525.

50. Yan SF, Ramasamy R, Schmidt AM. The RAGE axis: a fundamental mechanism signaling danger to the vulnerable vasculature. Circ Res. 2010;106(5):842-853.

51. Suga T, Iso T, Shimizu T, Tanaka T, Yamagishi S, Takeuchi $\mathrm{M}$, Imaizumi T, et al. Activation of receptor for advanced glycation end products induces osteogenic differentiation of vascular smooth muscle cells. J Atheroscler Thromb. 2011;18(8):670-683.

52. Zhu Y, Ma WQ, Han XQ, Wang Y, Wang X, Liu NF. Advanced glycation end products accelerate calcification in
VSMCs through HIF-1alpha/PDK4 activation and suppress glucose metabolism. Sci Rep. 2018;8(1):13730.

53. Isami F, West BJ, Nakajima S, Yamagishi SI. Association of advanced glycation end products, evaluated by skin autofluorescence, with lifestyle habits in a general Japanese population. J Int Med Res. 2018;46(3):10431051.

54. van Waateringe RP, Slagter SN, van der Klauw MM, van Vliet-Ostaptchouk JV, Graaff R, Paterson AD, Lutgers HL, et al. Lifestyle and clinical determinants of skin autofluorescence in a population-based cohort study. Eur J Clin Invest. 2016;46(5):481-490.

55. Xu L, Wang YR, Li PC, Feng B. Atorvastatin blocks advanced glycation end products induced reduction in macrophage cholesterol efflux mediated with ATP-binding cassette transporters G 1. Circ J. 2019;83(9):1954-1964.

56. Shimomura M, Oyama J, Takeuchi M, Shibata Y, Yamamoto Y, Kawasaki T, Komoda H, et al. Acute effects of statin on reduction of angiopoietin-like 2 and glyceraldehydederived advanced glycation end-products levels in patients with acute myocardial infarction: a message from SAMIT (Statin for Acute Myocardial Infarction Trial). Heart Vessels. 2016;31(10):1583-1589. 